\title{
De las Mancomunidades voluntarias y de las Agrupaciones municipales forzosas
}

\author{
Glosas a la sección $3 .^{2}$, capitulo $1 .^{\circ}$, tf́tulo $10^{\circ}$, libro $\mathbf{1 .}^{\circ}$, \\ DE LA LEY DE REgimen Local
}

A D. José Gascón y Marin, aut sr de los más notatles trabajos sobre Mancomunidades.

En los vocablos mancomunar, agrupar y asociar entra la idea de unir y juntar y, por lo tanto, la Mancomunidad, la Agrupación y la Asociación significan e implican la unión o reunión de personas, fuerzas, caudales o cosas para algún fin. Gramaticalmente, la voz apropiada parece ser la de Mancomunidad. La terminología, en esta materia, en la legislación municipal ha sido muy varia : en la Ley de 1877, se emplean los términos asociaciones y mancomunidades; en el Estatuto Municipal de 1924, se usan los de mancomunidades y agrupaciones, y en la Ley de 1935, se emplea el de agrupaciones intermunicipales.

La Ley de Régimen Local utiliza los términos mancomunidad, refiriéndose a las uniones voluntarias, y agrupación, refiriéndose a las asociaciones forzosas.

Las uniones municipales son el fruto de los principios de cooperación, solidaridad y auxilio mutuo, aplicables lo mismo a los individuos que a las colectividades públicas.

Por esto, la idea de unirse los pueblos para fines comunes ha 
germinado durante todas las épocas y ha ofrecido diferentes modalidades.

En España existieron desde fines del siglo xir uniones de pueblos que recibieron los nombres de Universidades, Hermandades, Germanías, Junterías, Federaciones y Comunidades. Las más notables fueron las Hermandades y Comunidades.

Las Hermandades tenían carácter marcadamente político. En la Carta de la Hermandad, pactada en 1282, entre los nobles, los Consejos de Castilla, León y Galicia y el Infante Don Sancho, se consigna, como derechos de los afiliados, contra los desafueros del mismo monarca, el derecho de insurrección ; contra los de sus oficiales y jefes, la facultad de los Concejos para juzgarlos, castigarlos y suspender sus providencias, y contra los agravios de los no afiliados a la Hermandad, el derecho de los Concejos a ir sobre ellos, derribarles sus casas y apoderarse de sus bienes.

Las Comunidades tenían como finalidad el aprovechamiento de los montes, aguas, pastos. En su origen fueron independientes de las formaciones municipales, si bien muchas veces eran administradas por los mismos organismos municipales. Se regían por normas consuetudinarias.

Las leyes desamortizadoras y la legislación local de la primera mitad del siglo xix hicieron muy difícil la vida de las entidades supramunicipales, y éstas desaparecieron o se refugiaron en el Derecho primitivo. Sin embargo, prontamente se reaccionó en el sentido de abrir un cauce jurídico a las Asociaciones existentes.

La complejidad de la moderna vida local ha hecho más notoria la necesidad de las uniones municipales, y éstas son actualmente objeto de regulación en todos los países, si bien con diferentes denominaciones: "Associations", en Bélgica; "Joint Boards", en Inglaterra; "Consorzi", en Italia ; "Sindicats", en Francia ; "Umions", en Rumania ; "Landbürgemeisterein", en Alemania...

Sin embargo, los trabajos de los Congresos de la Unión Internacional de Ciudades demuestran que en todos los países existe 
una repugnancia por parte de los Municipios a unirse entre ellos, incluso cuando la oportunidad se les presenta para hacerlo.

En nuestro país es muy reducido el número de asociaciones municipales. ¿ Por qué nuestros Municipios prescinden de las mancomunidades? ¿Por qué repugnan y se apartan de toda unión con otros Municipios? No es difícil contestar a estos interrogantes debidamente. De un lado el acentuado individualismo, la persistente indiferencia ante todo cuanto suponga rotura de viejos moldes, el apego a la rutina, la apatía para obrar diligentemente, han provocado más de una vez el aborto de las mancomunidades de pequeños Municipios, y de otro lado, rivalidades, resquemores avivados, pugnas personales y rencillas perennes entre los pueblos han frustrado, también, muchas convenientes uniones de Municipios.

Los precedentes legislativos de las Mancomunidades municipales deben buscarse en la Ley Municipal de 1877, que, en sus artículos 81 y 82, disponía que los Ayuntamientos podían formar entre sí y con los inmediatos asociaciones y comunidades para la construcción y conservación de caminos, policía y seguridad, aprovechamientos comunales, asistencia, instrucción y otros objetos de su exclusivo interés; y en cuanto a las agrupaciones forzosas-de las cuales no tenemos precedentes históricos, cosa natural, porque, hasta tiempos bastante recientes, la necesidad a que responden era o pretendía ser satisfecha mediante la fusión obligatoria de los pequeños Municipios-, los primeros antecedentes legales los hallamos en unos preceptos de la Instrucción de Sanidad del año 1904 sobre prestación de servicios facultativos y sanitarios en los pueblos de pequeña población y reducido presupuesto, y en unas disposiciones de los años 1921 y 1922, dirigidas a organizar y sostener las brigadas sanitarias provinciales. El Estatuto Municipal, en sus artículos 12 a 15, 111, 207 y 226, y el Reglamento de población y términos municipales de 2 de julio de 1924, en sus artículos 13 al 15 y 41, introdujeron de manera expresa en nuestro derecho público las agrupaciones municipales obligatorias. 
Somos partidarios de la existencia de Mancomunidades para vencer las dificultades de que adolecen en su desenvolvimiento los Municipios, y con nosotros lo son todos los más destacados tratadistas de Derecho Municipal. Güenechea señala que no hay nada más conveniente que las mancomunidades para ahorrar gastos de personal, mejorar servicios y obtener otras ventajas. Jordana de Pozas nos dice que la limitación económica o de otro orden de un Municipio puede ser superada mediante la acción coordinada de varios orros inmediatos. Alvarez-Gendín afirma que desde luego son muy convenientes estas asociaciones para el sostenimiento de ciertos servicios que pueden ser aprovechados por varios pueblos, economizando gastos y aun prestándolos con más perfeccionamiento. Ruiz del Castillo sostiene que los núcleos reducidos de población, que son la base de los pequeños y numerosísimos Municipios, requieren cada día con mayor apremio la constitución en régimen de mancomunidad para remediar su insuficiencia. Albi Cholbi señala que se ha buscado una fórmula para poner al alcance de los pequeños Municipios las comodidades urbanas y los servicios propios de las grandes ciudades, ella consiste en la cooperación intermunicipal, en la constitución de asociaciones comunales que aúnan, en colectividades supramunicipales dotadas de personalidad propia, los esfuerzos aislados de los pequeños Municipios, impotentes por si solos para acometer empresas de altos vuelos. Gascón y Marín, el reputado tratadista, abunda en la misma opinión...

El problema de las grandes aglomeraciones urbanas ha sido también enfocado hacia soluciones en que es factor necesario la asociación de Municipios, y hoy se declara unánimemente que la organización de las grandes ciudades en forma de una Unión o Mancomunidad de Ayuntamientos es altamente conveniente, representando la continuación en las grandes ciudades de la obra que el legislador ha realizado ya en el Municipio rural, y culminando en el "super municipio", tal como lo concebía el gran maestro Adolfo Posada, desarrollo del concepto de la Mancomunidad municipal y que, en forma descentralizada, es la solución menos violenta, amplia formación urbana con el de los núcleos menores pre- 
constituídos que se ven amenazados, cuando no absorbidos, por la ola invasora de la gran ciudad tentacular.

El tratadista inglés Lewis Abbot, al tratar de hallar el medio de que las entidades locales puedan atender todos los servicios que reclame la colectividad más exigente, recomienda la adopción de un sistema regional en el gobierno local; y el profesor francés M. Nicolás atribuye a la asociación de Municipios fuerza suficiente para mantener y salvar el mayor número de aquéllos cuya población se cuenta por docenas de habitantes.

La preferencia de los autores hacia las Mancomunidades como medio de fortalecer la Administración municipal es, pues, evidente.

Resumiendo: contra el parecer de algunos, estimamos la importancia de las mancomunidades municipales para llegar a la organización comarcal, unidad administrativa natural, y para salvar los inconvenientes que para la descentralización representan los pequeños Municipios.

Coincidimos con el parecer de Ortega y Gasset, en su obra La redención de las Provincias, cuando dice que la unidad política local no ha de limitarse a coincidir con lo que es hoy la vida local, sino que ha de contar, muy esencialmente, con hacerla capaz de empresas, de crecimiento, de magnificación... El Municipio, como institución, es una “jaula de codorniz»... El Municipio no es una unidad política completa, pero es real, como la mano no es un hombre entero... La Provincia, en cambio, no es ni eso, es simplemente un torpe tatuaje. La unidad política local es la gran comarca. Esta si que puede ser una gigantesca fuerza nacional... Para llegar a crearla es preciso impulsar a los Municipios a unirse en Mancomunidades. Estas pueden ser la simiente del resurgimiento nacional.

Aunque, como hemos indicado antes, nuestros Municipios tienen en puridad muy poco espiritu asociacionista, existen en nuestro país diferentes mancomunidades voluntarias, tales, por ejemplo: la Mancomunidad de los Ayuntamientos de Pineda y Torde- 
ra (Barcelona), para conservación, mejora y sostenimiento del camino de Puente de Pineda a Orsavinyá; la Mancomunidad de los Ayuntamientos de Maracena, Pulianas, Pulianillas y Jun, con inclusión de la Diputación Provincial de Granada, para abastecimiento de aguas; la Mancomunidad de los Ayuntamientos de Alicante, San Juan de Alicante, Muchamiel y otros para el sostenimiento del servicio de incendios; la Mancomunidad denominada "Entror", integrada por los Ayuntamientos de Enfesta, Trazo y Arosa (Coruña), para la construcción y sostenimiento de una casa cuartel para la Guardia Civil; la Mancomunidad de los Ayuntamientos de Usúrbil, Orio y Aya (Guipúzcoa), para la municipalización del suministro de luz y energía eléctrica; la Mancomunidad de los Ayuntamientos de Medina del Campo, Rueda, Tordesillas, Benavente y otros (Valladolid y Zamora), para la construcción y explotación del ferrocarril de Medina a Benavente; la Mancomunidad de los Ayuntamientos de Olot, Vall de Vianya y Begudá (Gcrona), para la creación y sostenimiento de Escuela Nacional de Primera Enseñanza; la Mancomunidad de los Ayuntamientos de Almazán, Matamala y Tardelcuende (Soria), a los efectos de tener un ingeniero $\mathbf{y}$ un ayudante de Montes comunes...

La Ley de Régimen Local de 16 de diciembre de 1950 dedica la sección $3 .^{\circ}$, del capítulo $10^{\circ}$, del título $1 .^{\circ}$, del libro $1 .^{\circ}$ (artículos 29 y siguientes) a las Mancomunidades voluntarias y a las Agrupaciones municipales forzosas $\mathrm{y}$, además, se refiere a las mismas en los siguientes preceptos: Art. 10, que atribuye la consideración o carácter de Entidades municipales a las Mancomunidad's y Agrupaciones; art. 58, que establece que el gobierno y administración de las Mancomunidades o Agrupaciones correrá a carog de los órganos que determinen sus respectivos Estatutos; artículo 121, letra $b$ ), que dispone que corresponderá al Ayuntamiento pleno la creación, modificación o disolución de Manconunidades; art. 139, que faculta a los Municipios para constituir Mancomunidades, para formular y ejecutar conjuntamente proyectos de urbanización; art. 181, sobre Agrupaciones forzosas decre- 
tadas para el caso de que la municipalización de un servicio afectare a varios términos municipales; art. 303, letra c), que exige quorum para la validez de los acuerdos de creación o disolución de Mancomunidades; art. 343, números 2 y 3, sobre creación por el Ministerio de la Gobernación de Agrupaciones intermunicipales a los efectos de sostener un secretario común y sobre el sueldo de éste; art. 350, número 5, sobre cumplimiento por las Mancomunidades y Agrupaciones de cuantos preceptos legales sobre funcionarios administrativos, técnicos y de servicios especiales estén en vigor o sean promulgados en lo sucesivo; art. 439, que declara que la Mancomunidad o Agrupación en que figure el Municipio de la imposición estará exenta de derechos y tasas por todos los aprovechamientos inherentes a determinados servicios; artículo 466 , que declara que las normas generales reguladoras de las contribuciones especiales son aplicables a las obras, instalaciones y servicios que realicen las Mancomunidades y Agrupaciones municipales; art. 468, sobre exención del pago de contribuciones especiales a favor de las Mancomunidades y Agrupaciones por los inmuebles de su pertenencia; art. 647, número 8, sobre aplicación a las Mancomunidades y Agrupaciones de las disposiciones sobre exenciones o beneficios fiscales de los Municipios en relación al Estado; art. 677, número 2, sobre normas reguladoras de los presupuestos de las Mancomunidades y Agrupaciones; arÉculo 679, número 1, letra $f$, sobre conceptuación de gastos obligatorios de los que dimanen del cumplimiento de pactos de Mancomunidad que el Municipio hubiere contratado, y art. 715, que dispone que los preceptos comunes a los sistemas de recaudación municipal son de aplicación a las Mancomunidades dentro de su competencia y régimen de Hacienda.

En materia de Mancomunidades voluntarias hay que tener en cuenta, asimismo, la disposición del artículo 74 de las Instrucciones de Montes de 17 de octubre de 1925, que dice así: "Los Ayuntamientos dueños de montes limítrofes, o que por su situación puedan agruparse en uno o varios que tengan extensión y existencias suficientes para ser objeto de ordenación, podrán constituirse en mancomunidad, con arreglo a lo dispuesto en el Estatuto Municipal. El Ministerio de la Gobernación oirá al de Fc. 
mento antes de aprobar los Estatutos de estas Mancomunidades."

$\mathrm{Y}$ en materia de Agrupaciones forzosas hay que tener en cuenta, también, las disposiciones siguientes :

La Base 22 de la Ley de Bases de Sanidad Nacional de 25 de noviembre de 1944, que regula, con el nombre de Mancomunidad, una agrupación intermunicipal forzosa: la Mancomunidad Sanitaria de Municipios de la provincia, con la finalidad principal del pago a los funcionarios sanitarios de sus haberes y del sostenimiento de los Institutos Provinciales de Sanidad, regida por una Junta Administrativa presidida por el Delegado de Hacienda.

Las Reales Ordenes de 27 de noviembre de 1923 y 26 de mayo de 1924 ; Reglamento de población y términos municipales de 2 de julio de 1924, art. 15 ; Real Orden de 21 de agosto de 1924 ; Ordenes de 13 de septiembre de 1943 y 24 de marzo de 1944 y Circular de 17 de noviembre de 1924, sobre Agrupaciones forzosas de los Municipios del partido judicial para atenciones de justicia ; y

La Base 8. de la Ley de Bases de la Justicia Municipal de 19 de julio de 1944 ; Decreto de 19 de enero de 1945, art. 33, y Circular de 13 de noviembre de 1945, sobre Agrupación forzosa de los Municipios de la comarca judicial para atenciones de justicia.

El examen y estudio de los preceptos de la Ley de Régimen Local sobre la materia nos sugiere los comentarios que pasamos a exponer :

I. La Ley de Régimen Local no pone traba alguna a los Ayuntamientos para la constitución de entidades supra o intermunicipales; el derecho de los Municipios a asociarse es el corolario lógico del reconocimiento de su libertad y autonomía.

Pueden existir mancomunidades de Municipios limítrofes y de otros que no lo sean; y las puede haber de Municipios de una misma provincia y de Municipios de provincias distintas.

Un problema se presenta: ¿Puede una Diputación provincial formar parte de una Mancomunidad voluntaria municipal? Entendemos que si bien la Mancomunidad municipal no admite por su esencia que pueda estar formada por otras entidades que no sean las municipales, en la práctica, mayormente dada la tendencia de la Ley de Régimen Local, hay que admitir el funciona- 
miento de uniones voluntarias intermunicipales con integración de las correspondientes Diputaciones provinciales. Un Decreto de 2 de noviembre de 1945 autorizó la formación de un Consorcio entre la Diputación de Zaragoza y diversos Ayuntamientos a los efectos de realizar las obras de abastecimiento de aguas y saneamiento de los pueblos respectivos, y otro Decreto de 7 de diciembre de 1945 aprobó la inclusión de la Diputación de Granada en la Mancomunidad de Nuestra Señora de las Angustias, formada por los Ayuntamientos de Maracena, Pulianas, Pulianillas y Jun, para el abastecimiento de aguas potables. En la provincia de Lugo se ha creado un Consorcio de la Diputación con los Municipios para obras y servicios comunales..., e incluso, como caso de intervención de organismos extraños al Municipio en una Mańcomunidad intermunicipal, podemos citar la Mancomunidad para el abastecimiento de aguas de Cartagena, Murcia y otras poblaciones, de la cual forma parte la representación de la Base Naval de Cartagena, según disposición del artículo 1 del Reglamento de 2 de marzo de 1928. Todo ello demuestra que está permitido que las Diputaciones provinciales formen parte de las uniones voluntarias intermunicipales.

II. Las Mancomunidades son uniones de "Municipios", no de pueblos ni de Ayuntamientos, es decir, que son los Municipios los asociados, aunque incumba al Ayuntamiento intervenir, como órgano supremo de la Administración municipal y su representante legal en todo cuanto afecta a aquéllas.

III. Los acuerdos de formación o creación de Mancomunidades adoptados por los Ayuntamientos interesados no necesitan la aprobación de Autoridad superior. Otra cosa es si se trata de acuerdos relativos a la aprobación de Estatutos y Ordenanzas.

IV. Lo lógico para la creación de una Mancomunidad es que un Ayuntamiento tome la iniciativa y se dirija a los demás, tal como expresa el artículo $7 .^{\circ}$ del Reglamento sobre población y términos municipales de 2 de julio de 1924. El acuerdo.de creación precisa el voto favorable de las dos terceras partes del número de concejales de hecho, y en todo caso de la mayoría absoluta legal de miembros de la Corporación. No es preciso, en cambio, quorum para el acuerdo de ratificación de los Estatutos (elabora- 
dos por la correspondiente Comisión) por parte de los Ayuntamientos integrantes de la unión.

V. Los acuerdos de las Mancomunidades, esto es, las decisiones de sus órganos de gobierno y administración, al igual que los adoptados por las Corporaciones municipales, agotan la vía gubernativa, siempre que recaigan sobre materias de su propia y exclusiva competencia, conforme establece la sentencia del Tribunal Supremo de 25 de septiembre de 1950.

VI. La Mancomunidad debe obrar en el ejercicio de sus actividades como persona jurídica, y no llenaría la finalidad que le pertenece si para el cumplimiento de sus peculiares fines no tuviera capacidad jurídica suficiente. Ahora bien; la determinación de esa capacidad la han de acordar las Corporaciones integrantes de la Mancomunidad al aprobar los Estatutos. Al fijarla, deberán tener presente que, para que la unión cumpla su cometido, deberá poder actuar sin trabas y sin limitaciones de ninguna índole. Puede servir de buena orientación en el particular la capacidad que la Ley de Régimen Local señala a Municipios y Entidades locales menores, y, desde luego, deberá tenerse en cuenta lo que exija la naturaleza de los fines que la Mancomunidad tenga asignados.

VII. Los elementos esenciales de las Mancomunidades, a tener en cuenta al elaborarse sus Estatutos, como observa Hernández Ruiz, pueden ser los siguientes: $1^{\circ}$, que las mancomunidades las forman, salvo excepciones, los Municipios ; $2 .^{\circ}$, que se constituyen por la libre voluntad de las corporaciones municipales interesadas; $3 .^{\circ}$, que sus fines han de ser únicamente de carácter administrativo, de la competencia municipal, o que, excediendo ésta, interesen a varios términos; $4 .^{\circ}$, que su actividad ha de ser la de cumplir uno o varios de estos servicios u obras, pero concretos y determinados; $5^{\circ}$, que su actuación ha de redundar en interés y beneficio común de los Municipios que la integran; $6 .^{\circ}$, que ella misma, en período de formación, es la que debe dictarse las normas porque haya de regirse; $7 .^{\circ}$, que posee plena capacidad jurídica; $80^{\circ}$, que cada uno de los Municipios que la forman ha de poder separarse cuando le convenga, y $9 .^{\circ}$, que su disolución ha de depender también de la voluntad de esos $\mathrm{Mu}$ nicipios. 
Desde luego los Estatutos de la Mancomunidad deben determinar claramente, concretamente, los fines de la misma. Velando por la pureza del concepto de la institución, el Gobierno tuvo necesidad de poner la oportuna cortapisa a un intento de constitución de una mancomunidad que se pretendía crear para fines no concretos y determinados, a saber, para todos los servicios que pudieran afectar y ser comunes a los Ayuntamientos. Por Real Decreto de 8 de enero de 1931, se declaró que los fines de la mancomunidad hay que individualizarlos y determinarlos especialmente. El expresado Real Decreto recogió dictamen del Consejo de Estado, que consideró la fórmula empleada por las Corporaciones locales de una vaguedad extraordinaria y como una suerte de autorización anticipada para constituir mancomunidades sustraídas al control de la Administración central, la cual perdería la potestad de señalar las posibles extralimitaciones legales en cada caso, por lo que estimaba necesaria la determinación concreta de cada uno de los fines u objetos para los que se ha de constituir la Mancomunidad.

Los Estatutos son el ordenamiento o conjunto de reglas, con fuerza de ley, que regula una institución. Por ello son indispensables para que la Mancomunidad exista. De ellos derivará la medida de su capacidad jurídica. La falta de los mismos, a pesar de los acuerdos que pudieren haber adoptado las Corporaciones interesadas, expresivos de la iniciativa y de la creación de la unión, deja a ésta sin vida; de ahí que para su perfección, para su existencia de hecho y de derecho, se requiera el cumplimiento inexcusable de este requisito.

VIII. En materia de extinción y disolución de la Mancomunidad, ya hemos indicado que es condición indeclinable de los Municipios el poseer plena libertad para apartarse de la asociación. Esta facultad, empero, tiene que sufrir alguna limitación en aras de la conservación de los intereses que haya creado la Mancomunidad. Por esto en los Estatutos habrá que determinarse cómo y cuándo podrá tener lugar el desglose de cualquiera de los Municipios asociados, con fijación de las normas y requisitos a que deba sujetarse la separación.

IX. Casos de agrupaciones forzosas son las de los Munici- 
pios del partido judicial y de la comarca judicial para atenciones de justicia; las de los Municipios para sostener un secretario común (art. 343 de la Ley de Régimen Local y Ley de 15 de diciembre de 1939); las de Municipios para municipalizaciones de servicios afectantes a varios términos comunales (art. 181 de la Ley de Régimen Local) y las de los Municipios de cada provincia para el pago de los haberes de los funcionarios sanitarios y sostenimiento de los Institutos Provinciales de Sanidad (Ley de Bases de la Sanidad Nacional de 25 de noviembre de 1944, base 22).

$\mathrm{X}$. Deben distinguirse perfectamente las Mancomunidades municipales de las Agrupaciones forzosas en razón a su distinta motivación. En las Agrupaciones forzosas no hay iniciativa municipal, ni libre decisión de las Corporaciones comunales, ni intervención de las Administraciones municipales en la aprobación de los estatutos, requisitos precisos y característicos de. las Mancomunidades voluntarias. La diferencia entre Mancomunidades y Agrupaciones ha sido fijada por el Tribunal Supremo en sentencia de 5 de octubre de 1932, en esta forma: "Las mancomunidades municipales se diferencian de las agrupaciones forzosas no en sus fines, que pueden ser los mismos, sino en su constitución, voluntaria en las primeras y obligatoria en las segundas, así como en que en la mancomunidad forman los Municipios una persona jurídica regida por organismo propio, la Junta correspondiente, mientras que la agrupación sólo constituye una reunión de Municipios, pero no origina una nueva personalidad.) En realidad, la Agrupación forzosa, cuya denominación debería suprimirse, es uno de los procedimientos a utilizar para solucionar los problemas que plantea modernamente la administración de los Municipios y responde al propósito de acentuar la eficacia en las administraciones municipales y su completa subordinación a las exigencias del interés general.

XI. Creemos que la obligatoriedad de las uniones administrativas de Municipios, que se ha ido dibujando a través de los proyectos de ley para la reforma municipal desde el año 1891, irá exıendiéndose cada vez más por así exigirlo la vida moderna y el creciente intervencionismo estatal.

Luis MARQués Carbó Doctor en Derecho 